\title{
A Preliminary Investigation of the Relationship of Transition Preparation and Self-Determination for Students With Disabilities in Postsecondary Educational Settings
}

Career Development for Exceptional Individuals 33(2) 80-94

(C) 2010 Hammill Institute on Disabilities

Reprints and permission:

sagepub.com/journalsPermissions.nav

DOI: I0.1 I 77/0885728809356568

http://cdei.sagepub.com

(S)AGE

\author{
Mary E. Morningstar', Bruce B. Frey', Patricia M. Noonan', Jennifer Ng', \\ Beth Clavenna-Deane', Perry Graves', Ryan Kellems', Zach McCall', \\ Mary Pearson', Diana Bjorkman Wade' and Kendra Williams-Diehm²
}

\begin{abstract}
This study examined the relationship between high school transition preparation (school and family based) and selfdetermination among postsecondary students with disabilities. Seventy-six participants from 4-year universities completed a two-part online survey. The first part of the survey measured three dependent variables: psychological empowerment, hope, and locus of control. The second part measured the independent variable quality of high school transition preparation. Correlational analyses were conducted between the quality of a student's high school transition preparation and perceived self-determination (i.e., psychological empowerment, hope, and locus of control). Although significant correlations existed among the scales used to measure self-determination, the relationships between high school preparation and the role of families and self-determination was of interest.
\end{abstract}

\section{Keywords}

family involvement, self-determination, postsecondary education, student-focused planning, correlation research

The 1990 reauthorization of the Individuals With Disabilities Education Act (IDEA) for the first time ensured greater student involvement in transition planning, which has lead to an increased focus on "engaging students in the transition and education planning as a means to promote self-determination" (Wehmeyer \& Field, 2007, p. 47). The 2004 reauthorization strengthened the involvement of students by adding the consideration of student strengths to the previously mandated focus on preference, interests, and needs when developing the transition plan (Konrad, Walker, Fowler, Test, \& Wood, 2008). The 2004 reauthorization also added language requiring the development of measurable postschool goals in the areas of employment, education/training, and, if appropriate, independent living. In addition, under IDEA 2004, states are now compelled to report student postschool outcome performance (Individuals With Disabilities Education Improvement Act, 2004), thereby amplifying the importance of tying transition planning and services to student postschool success. National organizations have acknowledged the need to increase student participation in postsecondary education and addressed that need by advocating for improved high school transition services, including instruction and opportunities to increase student self-determination (National Council on Disability, 2004a, 2004b).

Despite these efforts, the National Longitudinal Transition Study-2 (NLTS-2) has indicated that although the rates of college enrollment for out-of-school youth with disabilities have improved over the past 20 years, outcomes fall far below those of their peers without disabilities (Blackorby \& Wagner, 1996; Wagner, Newman, Cameto, Carza, \& Levine, 2005). Most recently, it was reported that $31 \%$ of youth with disabilities had enrolled in postsecondary coursework at vocational/trade schools, 2-year or community colleges, or 4-year colleges. Of those enrolled in postsecondary settings, the largest percentage (19\%) was enrolled in 2-year or community colleges. However, the rate of sustained

\footnotetext{
'University of Kansas

${ }^{2}$ University of Oklahoma

Corresponding Author:

Mary E. Morningstar, University of Kansas, Department of Special

Education, Room 52I JR Pearson Hall, I I 22 W. Campus Road, Lawrence, KS 66045

E-mail:mmorningstar@ku.edu.
} 
enrollment has remained low, with only $19 \%$ of youth with disabilities enrolled full-time in postsecondary settings as compared to $40 \%$ of youth from the general population (Newman, 2005).

\section{Self-Determination Preparation and Postsecondary Settings}

Research has indicated that providing instruction and opportunities in self-determination may improve the postschool outcomes of students with disabilities (Field, Sarver, \& Shaw, 2003; Wehmeyer \& Palmer, 2003). Unfortunately, providing this instruction and opportunity during high school to students with disabilities has occurred to varying degrees (Carter, Lane, Pierson, \& Glaeser, 2006; Mason, Field, \& Sawilowsky, 2004; Thoma, Nathanson, Baker, \& Tamura, 2002). Similarly, the practice of involving students with disabilities in their Individualized Education Plan (IEP) meetings has been inconsistently implemented across secondary programs. For example, Martin, Marshall, and Sale (2004) surveyed students, parents, and school professionals and found that although students attended $70 \%$ of IEP meetings, meaningful student participation appeared lacking. In fact, significant differences were reported between students and all other IEP team members. Students reported understanding far less about the reasons for the IEP meeting, what they needed to do during meetings, and what was said at meetings. Students also reported feeling significantly less comfortable saying what they thought and knowing what to do next. In a follow-up study, Martin et al. (2006) observed students during IEP meetings and the results indicated extremely limited student involvement during meetings (e.g., students spoke during 3\% of the intervals, as opposed to teachers who talked during $51 \%$ of the intervals and parents during $15 \%$ ). In addition, the percentage of meetings in which students contributed to the discussion was restricted. The most common contributions were expressing: interests $(49 \%)$, skills and limits (20\%), and goals (27\%). Martin et al. concluded that "for the most part, [they] only passively participated and simply served as token members - present at the meeting, but not involved in meaningful discussions or educational planning" (pp. 196-197). Despite ongoing research promoting long-term benefits of meaningful student involvement, it appears that the most widely instituted practice has been inviting and ensuring student attendance at meetings rather than actively supporting student decision making through the IEP process.

Self-determination has been defined as both a complex set of skills (e.g., problem solving, self-awareness, decision making) and organizational practices that provide opportunities for students to become self-determined (Wehmeyer, 2004). Specifically, self-determination has become an increasingly important skill for students with disabilities who transition to postsecondary education settings. To receive support services for an identified disability in a postsecondary setting, students must disclose their disability (Eckes \& Ochoa, 2005). Being able to request and manage critical postsecondary accommodations can present challenges for an individual with a disability who has not received foundational instruction in these processes (Eckes \& Ochoa, 2005; Finn, Getzel, \& McManus, 2008). Therefore, instruction and opportunities for self-determination while in secondary programs are critical transition services to facilitate improved success in postsecondary environments (Thoma \& Getzel, 2005). Clearly, more research is needed to better understand the impact that postsecondary skill preparation, IEP involvement, and self-determination instruction during high school have on the success of students with disabilities in postsecondary settings.

Research has indicated that certain components of selfdetermination have been beneficial for students with disabilities in postsecondary settings. Durlak, Rose, and Bursuck (1994) asserted that instruction in self-awareness and self-advocacy played a critical role in improving skills and academic experiences in postsecondary environments for individuals with disabilities. Others have recommended increasing self-advocacy skills during the secondary years in an effort to improve the ability of students to manage the postsecondary environment (Harris \& Robertson, 2001). These authors noted that a lack of preparation for the demands of the postsecondary environment accounted for difficulties in maintaining enrollment among students with disabilities.

Thoma and Getzel interviewed students in postsecondary settings to determine the necessity of self-determination instruction (Getzel \& Thoma,. 2008; Thoma \& Getzel, 2005). Participants indicated that self-advocacy, self-awareness, internal locus of control, goal setting, and decision making were necessary for their success in postsecondary settings. In addition, Hong, Ivy, Gonzalez, and Ehrensberger (2007) suggested that skills needed for students with disabilities to successfully transition to postsecondary settings could be obtained by providing instruction in self-advocacy, selfregulation, internal locus of control, and self-knowledge while in high school. Finally, Jameson (2007) conducted a study examining the level of self-determination of students with disabilities enrolled in community college settings and its relationship to postsecondary success (e.g., college retention, postsecondary grade point average, employment, and student descriptions of self-determined behavior). His conclusions supported the contention that higher degrees of self-determination, specifically in the area of psychological empowerment, correlated with higher degrees of success for students with disabilities in postsecondary settings. Although research supports the argument for instruction in selfdetermination while in high school to increase the likelihood 
of postsecondary success, less is known about the impact of secondary school self-determination instruction on improved postschool outcomes (Cobb \& Alwell, 2008).

\section{The Role of Hope and Postsecondary Settings}

Research in psychology has indicated that hope and motivation can predict academic success in both secondary and postsecondary environments for students without disabilities (Leeson, Ciarrochi, \& Heaven, 2008; Snyder et al., 2002). Hope has been defined as "goal-directed thinking in which people perceive that they can produce routes to desired goals (pathways thinking) and the requisite motivation to use those routes (agency thinking)" (Lopez, Synder, \& Pedrotti, 2003, p. 94). Babyak, Snyder, and Yoshinobu (1993) defined pathways as reflecting "an individual's perceived availability of ways to attain a goal" and agency as "the willful sense of determination and energy to meet goals" (p. 155). Agency and pathways are similar to elements of self-determination described by students with disabilities as necessary for success in postsecondary educational settings (Getzel \& Thoma, 2008; Jameson, 2007; Thoma \& Getzel, 2005). Unfortunately, little research exists that extends hope as a factor in postsecondary environments for students with disabilities. Indeed, only one study was identified that examined levels of hope in students with disabilities. Lackaye and Margalit (2008) examined levels of hope among students with learning disabilities (LD) in middle school and secondary environments. The results of this research suggested that students with LD who were high academic achievers demonstrated lower levels of hope and self-efficacy (27\%) than their peers without disabilities (55\%). The researchers concluded that high-performing students with LD appear to be more frustrated and overwhelmed than their high-performing peers without LD. The authors advocated for providing academic strategies to students with LD to decrease frustration, maintain academic productivity, and increase opportunities for self-efficacy, social efficacy, and increased positive self-perception as a means to increasing hope. Given the theoretical implications of the dimensions of hope as it parallels the field's definition of self-determination, as well as some evidence of high levels of hope as a predictor of postsecondary success in students without disabilities (Snyder et al., 2002), one purpose of this study was to extend research on hope to students with disabilities. It is important to better understand whether high levels of hope coupled with effective transition preparation can support students with disabilities in managing the increasing demands of postsecondary environments.

\section{Quality Indicators of Effective Secondary Transition Programs}

Research evidence of effective secondary transition programs points to certain services and practices that are more likely to lead to positive postschool outcomes including: (a) interagency collaboration (Noonan, Morningstar, \& Gaumer Erickson, 2008), (b) student-centered transition planning (Cobb \& Alwell, 2008; Martin et al., 2006; Test et al., 2004), (c) curriculum and instruction focused on specific postschool outcomes (Alwell \& Cobb, 2006; Powers et al., 2001), (d) family involvement (Lehman, Bassett, \& Sands, 1999; Morningstar, 1997; Morningstar, Turnbull, \& Turnbull, 1995), and (e) student self-determination (Cobb, Lehman, Newman-Gonchar, \& Alwell, 2008; Karvonen, Test, Wood, Browder, \& Algozzine, 2004; Wehmeyer \& Field, 2007). Models of quality transition practices have been developed (Kohler, 1997) along with methods for program evaluation (Kohler, 2007; Morningstar, 2006); however, research substantiating transition program indicators with improved postschool outcomes has not been sufficiently implemented (Greene \& Albright, 1995; Morningstar, KleinhammerTramill, \& Lattin, 1999).

For students preparing for postsecondary education, certain practices have been identified as factors leading to increased success in postsecondary environments including: self-advocacy, self-awareness, goal setting, involvement in IEP decision making, and postsecondary skills preparation. In addition, students with disabilities in postsecondary settings have responded that they would have been better prepared for the college environment with earlier success in college courses if they had received instruction on many of these skills while in high school (Jameson, 2007; Thoma \& Getzel, 2005). Therefore, an essential purpose of this study was to examine the relationship between quality school-based transition programs and postsecondary student self-determination.

It has long been noted that family involvement can play a critical role in the development of student self-determination (Wehmeyer, Morningstar, \& Husted, 1999). In fact, research has indicated that when families are highly involved and advocate for the needs of their child during high school, those students with disabilities demonstrate better self-advocacy skills in secondary and postsecondary education settings (deFur, Todd-Allen, \& Getzel, 2001; Morningstar et al., 1995; Newman, 2005). In addition, secondary programs that encourage family and student involvement during transition planning have been associated with greater attainment of postschool outcomes such as employment, postsecondary education, community living, and community engagement (Devlieger \& Trach, 1999; Lindstrom, Doren, Metheny, Johnson, \& Zane, 2007). In fact, Newman (2005) reported preliminary results from the NLTS-2 that high levels of 
parental involvement appeared to promote youth achievement. In particular, parental postschool expectations may affect various aspects of a student's and family's future, yet such expectations could be different between parents and students as well as between the family/student and the school (Newman, 2005; Thompson, Fulk, \& Piercy, 2001). Therefore, given the focus on transition preparation and postsecondary self-determination, identifying the potential influence of the role of the family is essential. Given this, an additional purpose of this study was to examine the relationship between the students' perceptions of the ability of their families to support them during transition planning and student levels of self-determination.

\section{Purpose of the Study}

Increasing the self-determination of students with disabilities while in high school is a promising approach to improving postsecondary educational outcomes (Getzel, \& Thoma, 2008; Harris \& Robertson, 2001). Additionally, transition programs that encourage active family engagement and high expectations among families and students appears to be beneficial (Newman, 2005). Finally, the importance of preparation for specific postschool skills such as selfdetermination has yet to be fully determined. Therefore, this study examined the relationship between student perceptions of the quality of their high school transition programs in preparing them with critical transition skills (i.e., self-determination, postsecondary skills) and their levels of self-determination in postsecondary educational settings. Figure 1 depicts the overall scope of the study depicting independent and dependent variables. Equally important was the focus on the self-reported role of the students' families in supporting them with opportunities for self-determination and the preparation for postsecondary settings. More specifically, the researchers examined the relationship between the perceived quality of a student's high school transition preparation as measured by student ratings of school-based and family-driven instruction and opportunities for self-determination and postsecondary skill preparation with components of postsecondary selfdetermination: (a) psychological empowerment, (b) hope, and (c) locus of control.

\section{Method}

\section{Participants and Sampling Procedures}

The researchers recruited participants through a convenience sample of college students with disabilities from eight public 4-year colleges and universities and four community colleges. The postsecondary settings were located in five states that represented several regions of the United States: Midwest, West, Southwest, and Northwest. The researchers contacted disability services personnel at the schools and asked them to send electronic mailings to students and to post fliers about the study. The electronic mailings and fliers included a Web address that connected the students directly to an online survey where the students were required to give consent before completing the survey. Students received a cash stipend and a small gift for participating in the study.

The criteria for participant inclusion in the study were students who reported having an IEP while in high school and who had graduated during or after 1997. The researchers chose this cutoff date because the IDEA reauthorization of 1997 amended and strengthened the transition requirements. Seventy-six students qualified and completed both sections of the online survey. These students ranged in age from 18 to 29 , with a mean age of 22 .

Participants answered demographic questions about their gender, year in college, high school state, and college state. In addition, students were asked to identify their disability from among the 13 disability categories defined by IDEA 2004 or select "other." The final sample included participants from eight colleges or universities and one Native American university. Participants attended high school in 17 states as well as 3 territorial, military, or American schools outside the United States.

\section{Survey Development}

The online survey consisted of two sections. The first section used validated measures to determine participants' perceived levels of self-determination, hope, and locus of control. The researchers selected the Psychological Empowerment subscale of the The Arc's Self-Determination Scale (Wehmeyer \& Kelchner, 1995), the How I Feel About Myself Scale (Rehfeldt, 2006), and the Adult Trait Hope Scale (Snyder et al., 1991). The researchers did not alter the scoring or the wording of the measurements when posting survey items to the online and fully accessible survey Web site, developed using EZSurvey software (Raosoft, 2007). EZSurvey was chosen because it allowed for the development of online surveys in compliance with Section 508 of the Rehabilitation Act (1998) § Rehabilitation Act of 1973, Pub. L. No. 93-112, 87 Stat. 355, Section 508 as amended 29 U.S.C. $\S 794$ (d) and was fully accessible to screen readers used by individuals with visual impairments.

The scales chosen assessed certain dimensions of selfdetermination that have been identified as variables influencing postsecondary success: self-advocacy, self-efficacy, internal locus of control, and capacity for goal setting and decision making (Getzel \& Thoma, 2008; Jameson, 2007; Thoma \& Getzel, 2005). The Psychological Empowerment scale (Wehmeyer \& Kelchner, 1995) was selected because it measures perceived levels of internal locus of control, selfefficacy, and outcome expectancy. The Psychological Empowerment scale was normed with a sample of students 


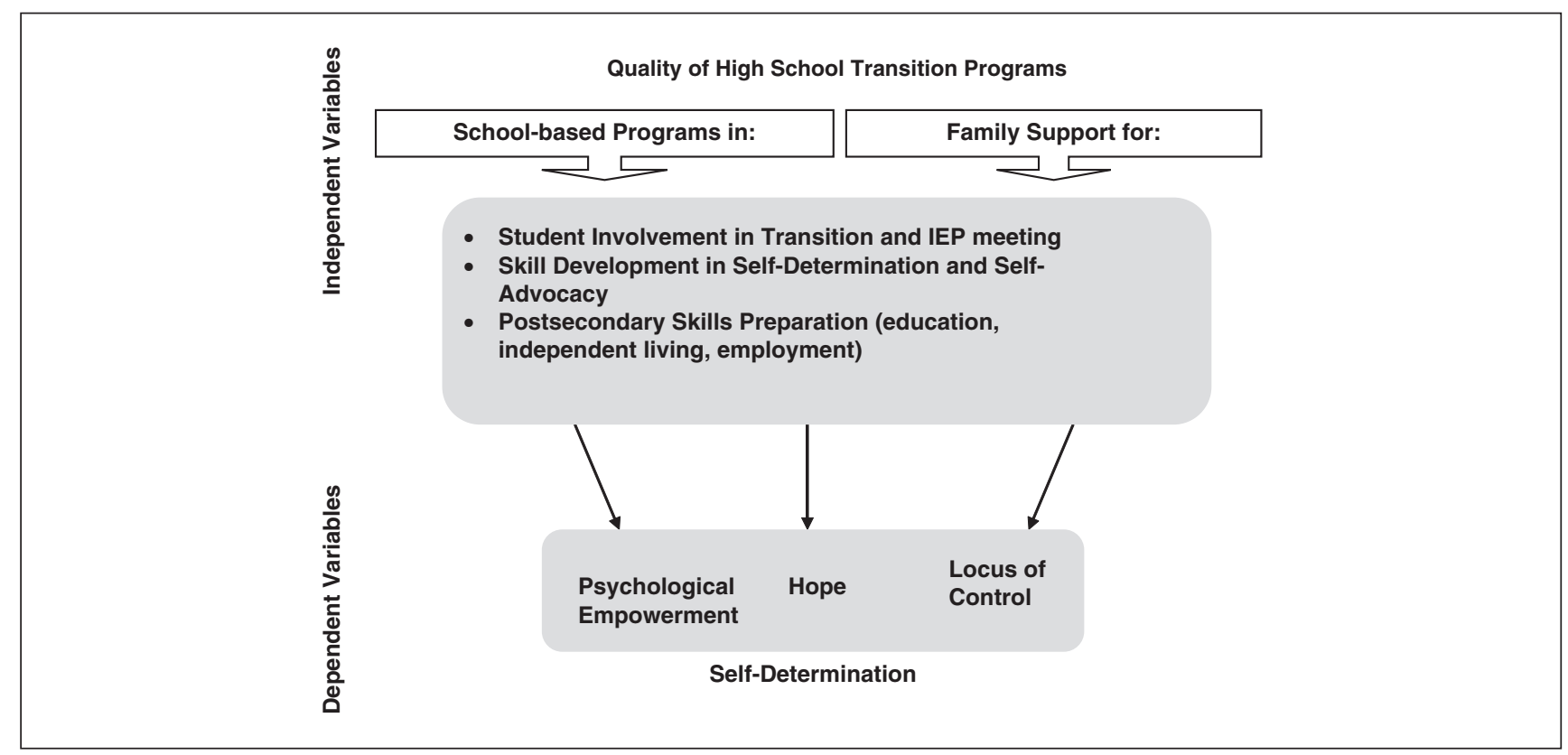

Figure I. Conceptual Model:Transition Preparation and Self-Determination in Postsecondary Settings

with various disabilities including $\mathrm{LD}$, emotional and behavior disorders, and intellectual disabilities (Wehmeyer, 1995). The How I Feel About Myself Scale measured personal beliefs regarding participants' perceived locus of control over decisions related to his or her transition to adulthood (Rehfeldt, 2006). Participants in Rehfeldt's (2006) research included students with LD, intellectual disabilities, and emotional and behavior disorders. Finally, the Adult Trait Hope Scale (Snyder et al., 1991) measured the variables of hope: agency and pathways. The use of the Adult Trait Hope Scale provided an indicator of capacity for goal setting and decision making, considered to be key components beneficial to students with disabilities in postsecondary settings (Getzel \& Thoma, 2008; Thoma \& Getzel, 2005). Snyder et al. (1991) originally developed and normed the scale with college students without disabilities and patients in psychiatric care. Subsequent studies have used the Adult Trait Hope Scale to examine the academic achievement of students with disabilities in high school (Lackaye \& Margalit, 2008), and an analogous scale for adolescents, the Children's Hope Scale (Snyder et al., 1997), has been shown to yield comparable results for high school students with and without intellectual disabilities (Shogren, Lopez, Wehmeyer, Little, \& Pressgrove, 2006). From previous studies, internal reliability estimates for the three measures ranged from good to excellent: (a) Psychological Empowerment scale, coefficient alpha $=.73$ (Wehmeyer \& Kelchner, 1995); (b) Adult Trait Hope Scale, .86 (Snyder et al., 2002); and (c) How I Feel About Myself Scale, .91 (Rehfeldt, 2006).
The second section of the survey, Quality of High School Transition Preparation, asked the participants to self-rate the quality of their high school transition programs pertaining to domains of their family's involvement in preparing them for adulthood and the capacity of the school program to provide instruction and opportunities for self-determination and postsecondary preparation. For this section of the survey, the researchers identified overlapping variables of high-quality secondary transition programs as identified by transition program evaluation measures including the TransQual (Brewer, 2006), Taxonomy for Transition Programming (Kohler, 1996), and the Quality Indicators of Exemplary Transition Programs Needs Assessment (Morningstar, 2006). Specific survey items from the NLTS-2 (Wagner et al., 2005) were also used to determine common variables of transition programs. From this literature, the researchers identified five types or categories of secondary transition indicators that specifically focused on self-determination and postsecondary preparation: (a) student involvement in transition planning and IEP meetings, (b) skill development and opportunities for self-advocacy and self-determination, (c) postsecondary education preparation, (d) independent living preparation, and (e) career preparation. Using these categories, the authors completed a qualitative content analysis that identified 50 indicators across all instruments. These items fell into one of three categories: (a) student involvement in transition and IEP planning, (b) skill development and opportunities for self-determination, and (c) postsecondary outcome preparation (e.g., independent living, career, and postsecondary preparation). The next phase in the 
content analysis involved identifying common features among the 50 items, which resulted in 18 items across the three categories (six questions per category, see the appendix). Participants were required to select one of three responses reflecting differing levels of intensity of the activity. For example, the question related to attendance at IEP transition meetings - "When you were in high school, did you go to your IEP meetings every year?"-included the following three responses:

I was invited to and attended my IEP meetings every year. My involvement in the meeting was supported by the school and my family

I went to some of my IEP meetings, but not every time. Sometimes I did not go because either I was not invited, my parents didn't want me to attend, or the meeting was not convenient with my schedule

I did not go to any of my IEP meetings.

To determine the influence of families as compared to that of the school, certain items that pertained to supporting self-determination were written to reflect either family or school support. For example, related to opportunities for advocacy, both of these questions were presented to participants: "What were some opportunities you had in school to advocate for yourself?" and "What were some opportunities you had at home to advocate for yourself?" Items from the survey focusing specifically on school support for self-determination and were compiled into a domain variable for school involvement. The family involvement domain variable was calculated using items on the survey that specifically asked about the family's support role.

Reliability analyses were conducted on the Quality of High School Transition Programs section of the survey, and coefficient alphas were computed. The overall estimate of reliability for all 18 items included in the survey produced a .91 coefficient alpha. The coefficient alpha estimates of reliability for the various subscales were: student involvement in transition and IEP processes (.88), skill development in self-determination (.67), postsecondary outcome preparation (.81), as well as across the two variables of family involvement (.81), and school involvement (.80). These estimates indicated high overall reliability and above average to high internal consistency for the subscales (Green \& Salkind, 2008).

\section{Results}

\section{Participant Demographic Information}

A total of 76 participants completed the survey. The majority of participants $(65 \%)$ identified their disability category
Table I. Descriptive Statistics

\begin{tabular}{lrrr}
\hline Variable & $M$ & SD & $\alpha$ \\
\hline Perceived levels of self-determination & & & \\
$\quad$ Hope & 6.51 & 0.98 & .84 \\
Psychological empowerment & 14.14 & 1.87 & .59 \\
$\quad$ Locus of control & 3.16 & 0.29 & .76 \\
Quality of high school transition program & & & \\
Quality of high school program total score & 2.35 & 0.44 & .91 \\
Student involvement in IEPs & 2.34 & 0.65 & .89 \\
Skill development in self-determination & 2.37 & 0.43 & .67 \\
Postsecondary skill preparation & 2.35 & 0.46 & .81 \\
Family involvement & 2.67 & 0.43 & .81 \\
School involvement & 2.12 & 0.50 & .80 \\
\hline
\end{tabular}

Note: $N \approx 76$. Scores for high school program total, family involvement, school involvement, student involvement, skill development, and postsecondary preparation all used a I to 3 scale. Means were calculated based on total number of items per domain. Hope scores use a I to 8 scale, psychological empowerment scores use a 0 to 16 scale, and locus of control uses a I to 4 scale. IEP = Individualized Education Plan.

as learning disability, with emotional disabilities (8\%), physical disabilities (6\%), visual impairments (5\%) and "other" $(5 \%)$ as the next most prevalent groups. The sample had slightly more females (54\%) than males (46\%). Students ranged in age from 18 to 29 years of age; however, the majority of students fell between the ages of 18 and 23 $(84 \%)$. In terms of ethnicity, the majority of students identified themselves as White (83\%), with Native American (5\%), Asian (4\%), African American (3\%), Other (2\%), and Latino (1\%) making up the rest of the group. Almost one third of the respondents $(29 \%)$ identified being in their $3 \mathrm{rd}$ year at the university, with approximately $20 \%$ reporting being in their 1st, 2nd, or 4th years, respectively, and about $5 \%$ indicating enrollment in graduate school. The majority of the respondents (91\%) were enrolled in 4-year colleges or universities including the Native American University, with only $9 \%$ from community colleges. The majority of the university students represented the three largest universities from three states (74\%), with the $25 \%$ distributed among the other five university settings.

\section{Correlational Data}

Table 1 presents descriptive statistics (means, standard deviations, and sample-specific coefficient alphas) for the variables related to quality of high school program (student involvement, self-determination skill development, postsecondary preparation) across the domain variables of family involvement and school involvement as well as the variables focused on postsecondary self-determination (i.e., hope, psychological empowerment, locus of control).

The purpose of this study was to ascertain relationships between and among variables associated with school-based and family-driven transition experiences and preparation 
Table 2. Pearson Correlation Coefficients

\begin{tabular}{|c|c|c|c|c|c|c|c|c|c|}
\hline Variable & I & 2 & 3 & 4 & 5 & 6 & 7 & 8 & 9 \\
\hline I. Hope & - & $.63^{* *}$ & $.52 * *$ & $.38 * *$ & $25 * *$ & $.37 * *$ & $.39 * *$ & $.47^{* *}$ & $.30 * *$ \\
\hline 2. Psychological empowerment & & - & $.44^{* *}$ & $.34^{* *}$ & $.27 * *$ & $.36 * *$ & $.25 *$ & $.40^{* *}$ & .20 \\
\hline 3. Locus of control & & & - & $.30 * *$ & .18 & $.26 *$ & $.34 * *$ & $.42 * *$ & .22 \\
\hline 4. High school transition program & & & & - & $.87^{* *}$ & $.83^{* *}$ & $.84 * *$ & $.72 * *$ & $.86^{* *}$ \\
\hline 5. Student involvement in IEPs & & & & & - & $.56 * *$ & $.56 * *$ & $.44^{* *}$ & $.59 * *$ \\
\hline 6. Self-determination skill develop & & & & & & - & $.66 * *$ & $.72 * *$ & $81 * *$ \\
\hline 7. Postsecondary Skill Preparation & & & & & & & - & $.77^{* *}$ & $.85^{* *}$ \\
\hline 8. Family involvement & & & & & & & & - & $.54 * *$ \\
\hline 9. School involvement & & & & & & & & & - \\
\hline
\end{tabular}

Note: IEP = Individualized Education Plan.

${ }^{*} p<.05$ level (two-tailed). ${ }^{* *} p<.0$ I level (two-tailed).

and dimensions of postsecondary self-determination. Correlations among all variables were calculated, and the coefficients are shown in Table 2. Overall, the six measures of high school transition program quality (an overall score, three subscales, and two domains) were moderately associated with current levels of hope and psychological empowerment among students with disabilities in college, and with student perceptions of internal locus of control during their high school transition process. Significant correlations of the transition program variables ranged from .25 (degree of student involvement in the transition IEP process with current levels of hope) to .47 (level of family involvement in the transition process with current levels of hope). The overall index of high school transition program moderately correlated $(p<.01)$ with perceived levels of hope (.38), psychological empowerment (.34), and perceived locus of control (.30).

The role families played in supporting and promoting student self-determination was found to be moderately correlated $(p<.01)$ for hope $(.47)$, psychological empowerment (.40), and locus of control (.42). The correlations associated with school involvement domain variable showed the weakest correlations, with the dimension of selfdetermination moderately correlating only with the hope scale $(.30 ; p<.01)$. The school involvement domain variable did not show significant correlations with locus of control or psychological empowerment.

Breaking down the high school program variables and comparing these with postsecondary self-determination levels resulted in some unexpected findings. The selfdetermination skill development variable, often considered a cornerstone of transition preparation, showed small to moderate correlations $(p<.01)$ with hope $(.37)$ and psychological empowerment (.36), and a low correlation with locus of control $(.27 ; p<.05)$. The student involvement in transition IEP variable correlated with hope (.25) and psychological empowerment $(.27$; both $p$ s $<.01)$. The third programmatic area, postsecondary skill preparation, correlated with hope $(.39 ; p<.01)$ and locus of control
$(.34 ; p<.01)$ at a moderate level, but to a lesser extent with psychological empowerment $(.25 ; p<.05)$.

Finally, the relationships among the three dimensions of self-determination used in the study revealed significant and strong correlations between hope and psychological empowerment $(.63 ; p<.01)$, as well as hope and locus of control $(.52 ; p<.01)$, and between psychological empowerment and locus of control $(.44 ; p<.01)$. Finally, postsecondary grade point average exhibited lesser correlations with the three self-determination scales.

\section{Discussion}

\section{Limitations of Study}

Further research is needed to address the limitations of the present study. First, a large portion of the sample consisted of students with LD, indicating a smaller percentage of all the other possible categories of students with disabilities in postsecondary settings. Students with LD make up the largest percentages of individuals with disabilities attending postsecondary settings (Newman, 2005); however, our sample may not be representative of the population of students with disabilities attending postsecondary settings and receiving disability support services. Although the recruited postsecondary institutions represented a diverse group of states from various regions of the United States, the institutions were not randomly selected but were chosen based on a convenience sample, as were the students who responded to the requests to participate. Random sampling across states, types of postsecondary institutions, and students would have improved the ability to generalize these results. In addition, the limited sample of participants from 2-year and community colleges further inflated the responses of students with disabilities at 4-year universities.

Recruiting postsecondary students with disabilities from support services personnel presents further limitations. Notably missing were students with disabilities not affiliated with support services. Therefore, the possibility that their 
experiences would have provided further insight to this study was not possible. Inherently, students already receiving postsecondary support services are more likely to have higher levels of self-determination as evidenced by their willingness to seek out contact with support services. Although this study specifically sought these individuals to better understand how high levels of self-determination were developed while in high school, it is difficult to ascertain whether these results were influenced by transition programs or the postsecondary disabilities services the students were receiving. We did not collect demographic information regarding the extent and nature of services provided to the students in this sample, and that is clearly an area for further study. Although we anticipated higher levels of selfdetermination, the limited range of our results was unanticipated, and further research is needed to extend and confirm these results.

\section{Summary of Results}

The participants in this study generally had high levels of psychological empowerment, locus of control, and hope, and this appeared to be related to certain components of high school transition programs, especially when families were supportive. This finding confirms previous qualitative research reporting that college students with disabilities attribute their success in postsecondary environments to learning and practicing self-determined behavior (Getzel \& Thoma, 2008; Jameson, 2006; Thoma \& Getzel, 2005). Students in Getzel and Thoma's (Getzel \& Thoma, 2008; Thoma \& Getzel, 2005) studies and Jameson's (2006) study described self-advocacy, psychological empowerment, and locus of control as necessary components of self-determination for students with disabilities in postsecondary environments.

Moderate to high levels of psychological empowerment and locus of control can help students with disabilities in postsecondary environments to become better advocates, which can lead to more successful postsecondary experiences. In addition, research has indicated that the ability to make and follow through with goals and decisions with high levels of motivation (i.e., hope) can increase the potential for success in postsecondary settings for the general population of students (Snyder et al., 2002). Because of the paucity of research on the relationship between hope and individuals with disabilities in postsecondary settings, this study offers preliminary evidence of validity for the use of the Hope Scale with students with disabilities in postsecondary settings. In addition, the results indicated moderate to high correlations between the Hope Scale and the scales for psychological empowerment and locus of control, both of which were designed specifically for students with disabilities.

Since the 1990 reauthorization of IDEA, transition planning and services have been a requirement for inclusion in
IEPs. High school transition programs have been charged with enhancing and increasing self-determination skills for adolescents with disabilities as a way to facilitate success after high school. According to the transition literature, a high-quality program should contain curricula, activities, and opportunities that promote self-determination throughout the student's secondary school experience (Brewer, 2006; Kohler, 1996; Morningstar, 2006).

The present study extends the research of possible links between high-quality transition programs and postsecondary self-determination among students with disabilities. The correlational analyses indicated that there was a moderate relationship between students with disabilities who were involved in their transition and IEP planning and had opportunities for self-determination skill development, and the components of hope and psychological empowerment. Therefore, this study does offer additional support for the importance of providing school experiences to students that focus on learning to be an active member of their IEP team and supporting students to make decisions both during transition meetings and throughout their academic environments. In addition, these results offer evidence that school-based instruction in self-advocacy skills is an important element of quality school programs and in fact correlates with selfdetermination among postsecondary students with disabilities. Our results also offer evidence that students who reported higher levels of self-determination were those who had opportunities and instruction related to postsecondary skill development.

When comparing high school program elements pertaining to self-determination skill development and preparation for postsecondary environments, the findings indicated small to modest relationships. Our findings suggest that students with disabilities in higher education settings who display high personal levels of psychological empowerment, hope, and locus of control likely have experienced higher quality high school programs, but it is not clear whether this is a causal relationship. More research is clearly needed.

Interestingly, some of the strongest correlations, albeit moderate in strength, were between the role the family plays in supporting students during transition and the students' involvement in IEPs, as well as opportunities to make decisions and plan for postschool outcomes. This was particularly evident for students who indicated high levels of involvement and support from their families. In fact, it appears that the influence of families was the only variable to exhibit moderate to high correlations across all three dimensions of self-determination. These results lend credence to efforts to encourage schools to promote family involvement during transition planning. This will require that families are not only informed about transition planning but take an active and supportive role in their child's preparation for the future. 
Given these results, secondary special education programs would benefit from recognizing the significant correlations between family involvement and support for students during transition planning and postsecondary student self-determination. The results of our study indicated that the more involved students perceived their families to be, the greater the students' perceived levels of locus of control, psychological empowerment, and hope. These results confirm previous research (deFur, Todd-Allen, \& Getzel, 2001; Morningstar et al., 1995) that has demonstrated the preference of students that their families (including extended family members) be highly involved in planning for postschool outcomes. Of course, additional research is needed to identify the specific impact of family involvement for increasing student self-determination with regard to locus of control, psychological empowerment, goal setting, and motivation (i.e., hope). Furthermore, the results from this study show moderate relationships between variables of quality high school programs and hope, psychological empowerment, and locus of control. However, because this research was correlational in nature, future research is needed to establish causal relationships among the components of high school transition preparation, including the influence of families and postsecondary self-determination and, by extension, postsecondary success.

These results extend the research focused on identifying effective practices for secondary programs that support opportunities for self-determination and the importance of successfully preparing students for the differences between secondary environments and postsecondary settings (Harris \& Robertson, 2001; Hong et al., 2007). The results of this study also demonstrate moderate support for considering self-determination - as represented here in the constructs of hope, psychological empowerment, and locus of controlas a critical foundation for success in postsecondary settings for students with disabilities (Durlak et al., 1994; Getzel \& Thoma, 2008; Jameson, 2007).

\section{Appendix: Quality of High School Transition Preparation Survey Items}

\section{Section I: Student Involvement in Transition Planning/IEP Meetings}

The first set of questions is about the special education meetings you had during high school. These might have been called an IEP (Individualized Education Plan) or ARD (Annual Review of Documents) meeting. During the meetings you, the school staff (teachers, principal, others), and your parents discussed your progress and developed both academic and future goals. You may have gotten out of class to go to a meeting or the meetings might have been before or after school. Please pick the response that best fits your experiences with IEP/ARD meetings.

\section{When you were in high school, did you go to your IEP meetings every year?}

a. I was invited to and attended my IEP meetings every year. My involvement in the meeting was supported by the school and my family.

b. I went to some of my IEP meetings, but not every time. Sometimes I did not go because either I was not invited, my parents didn't want me to attend, or the meeting was not convenient with my schedule.

c. I did not go to any of my IEP/ARD meetings.

\section{Describe your involvement in your IEP meetings.}

a. My family and I were active participants. The school supported our involvement. My input was listened to by the IEP team. I took the lead during the meeting on some occasions and my input was valued and listened to by the rest of the committee

b. My family and I provided some input. I agreed with most decisions, but my role was fairly passive. I had a few chances to provide input. When I did have input, it was because I or my family strongly believed in something. I sometimes led parts of the meeting, but did not feel encouraged to do so

c. My family and I attended meetings, but did not actively participate during IEP/ARD meeting. The school staff ran the meetings and did not often ask for input from us. I did not lead any of the meetings and neither did my family.

\section{How were your interests and goals for the future included in your IEP/ARD?}

a. My IEP goals accurately reflected what my interests and preferences were at the time. My future goals were developed with input from me and my family. If there were conflicts they were resolved in a positive way.

b. My preferences and interests were sometimes considered when developing my IEP goals, but they were mostly decided by the school. Sometimes certain goals were added only when I or my family spoke up. If there were conflicts they were not always resolved.

c. The goals were developed by the school without my input and did not include my preferences and interests. If there were conflicts, they were not resolved or left bad feelings. 


\section{Appendix (continued)}

\section{How were your IEP plans developed during meetings?}

a. My school program was planned primarily during my IEP/ARD meeting and a plan for achieving my post-school goals was included. I was involved in this planning for my future.

b. The school staff primarily created the plan for the future, but it was not always related to my post-school goals. I was somewhat involved in planning with the school.

c. The planning process completed during meetings did not address my post-school plans and the plan was always decided by school staff. I was not involved in planning for my future.

5. What other kinds of things happened in your IEP meetings besides talking about your goals for the future?

a. Test scores and other related data were explained to me and my family, and we could give input about these results. Together, we used this data to determine courses I should take and support I needed in my classes.

b. If transition assessment data was discussed it was only during the meeting and not before or after. I was not always involved in decisions about my IEP goals. Supports and accommodations I needed in class were identified by the school without my input.

c. The classes I wanted to or needed to take were not discussed with me, and no transition assessment data was discussed. The supports and accommodations I needed to be successful in my classes were never discussed or included in my IEP.

\section{How useful were the IEP meetings to you in planning} what you wanted to do after high school?

a. My IEP meetings prepared me and my family for postsecondary education, employment, and living on my own. I was happy with the outcomes of my IEP meetings.

b. My IEP meetings prepared me somewhat for postsecondary education, employment, and living on my own. I was somewhat happy with the outcomes of my IEP meetings.

c. My IEP meetings did not help prepare me for the future. The meetings may have been a barrier that prevented me from achieving my goals.

\section{Section 2: Skill Development in Self-Advocacy and Self-Determination}

The next set of questions are about experiences and opportunities that you had during high school to learn how to advocate for yourself. Advocating for yourself means to speak up for yourself, express your opinions, and make your own decisions about school and your future. For these questions, we'd like you to think about what happened on a daily basis during high school. Please pick the response that best fits your experiences with learning how to advocate for yourself.

7. While you were in high school, how did you learn about how to speak up for yourself?

a. I had classes during high school that helped me learn to advocate for myself and make decisions about my future such as personal planning, choicemaking, and goal setting. Teachers encouraged and instructed me on how to speak up for myself both in high school and outside of school

b. In my resource room classes or academic classes, I had conversations and meetings with teachers about how to speak up for myself, and how to make decisions. I didn't have any specific classes or direct instruction on these topics.

c. I had few or no experiences at school that taught me how to speak up for myself and make choices and decisions.

8. What were some opportunities you had in school to use your advocacy skills?

a. Teachers scheduled time with me, in addition to IEP meetings, to discuss my plans for my future. We discussed things like personal decision making, what classes to take, and how to solve problems related to advocacy. I met one-on-one with teachers or other school staff.

b. I scheduled time with teachers to talk about problems and plan for my future. The teacher or school staff did not arrange the meetings and they were more informal in nature. If I had problems, I would ask for help from my teachers.

c. I had few or no opportunities at school to talk about problems and learn how to speak up for myself. 


\section{Appendix (continued)}

9. What were some opportunities you had in school to use your advocacy skills?

a. Teachers scheduled time with me, in addition to IEP meetings, to discuss my plans for my future. We discussed things like personal decision making, what classes to take, and how to solve problems related to advocacy. I met one-on-one with teachers or other school staff.

b. I scheduled time with teachers to talk about problems and plan for my future. The teacher or school staff did not arrange the meetings and they were more informal in nature. If I had problems, I would ask for help from my teachers.

c. I had few or no opportunities at school to talk about problems and learn how to speak up for myself.

10. In thinking about your opportunities to advocate for yourself, how often did you have these opportunities at school?
a. A lot
b. Some
c. Little to none

11. In thinking about your opportunities to advocate for yourself, how often did you have these opportunities experiences at home?
a. A lot
b. Some
c. Little to none

\section{Section 3: Post-Secondary Outcome Preparation}

The last set of questions are about how you learned about things like going to college, having a job, and living on your own. We want to know whether you had a chance while in school to learn these skills and how your family helped you to achieve these skills. Please pick the response that best fits your experiences with preparing for post-secondary outcomes.

12. How would you describe the kinds of things you learned in high school that helped you get ready for college?

a. I learned skills in class lessons that included topics such as: study skills, instruction on completing college applications, advocating for disability services in college, how to disclose my disability, organizational skills.

b. My teachers sometimes discussed things I needed to know in college, but I had no real classes or instruction on the skills I needed.

c. My teachers never discussed, and I never had classes on, skills I would need in college. I had few or no opportunities to discuss the skills I would need in college with my teachers.

13. How would you describe the kinds of things you learned at home that helped you get ready for college?

a. My family and I participated in actual activities to help prepare me for college including: visiting college campuses, filling out financial aid forms, helping me complete college applications, helping me learn how to study.

b. My family and I discussed college informally, but actual activities did not take place. For example, we talked about going to college, but we did not visit any college campuses.

c. My family was not involved at all with my decision to go to college. They did not help me with any part of college and sometimes were a barrier to my attendance. I had to do most of the work.

\section{What kinds of job and career skills did you learn in} high school?

a. I had many job experiences while attending my high school. I learned career skills through classes and actual job experiences organized by my high school, such as: vocational classes, work study programs, or a career assessment.

b. I had a little job experience in high school. I learned a few job skills in my classes, such as: talking about good work habits, meeting with transition coordinators, or completing career assessments.

c. I had few or no experiences in high school that helped me learn career skills.

\section{Did you learn any job and career skills at home} when you were in high school?

a. My family often discussed and taught me job skills and good work habits. They also actively helped me find a job or supported me in finding a job and talked to me about problems that came up at work. 
b. My family sometimes talked about job skills and good work habits. They didn't actively help me find a job or help me with problems that came up at work.

c. My family was not involved in helping me find a job and we never talked about job skills. Sometimes my family was a barrier to me learning good job skills.

\section{What things did you learn in high school that helped you be able to live on your own?}

a. I learned many things during class in high school that have helped me live on my own. Some of these things included: independent living skills, banking skills, paying bills, meal planning, budgeting, how to get around in the community, how to get an apartment

b. I learned some things in high school that have helped me live on my own, but most of it was not taught in a formal way. Mostly, my teachers just talked about such skills, but we never really had chances to practice what we talked about.

c. I had few or no experiences in high school that helped me live on my own.

\section{What things did you learn at home that helped you be able to live on your own?}

a. I learned many things at home that have helped me live on my own. My parents talked about how to be successful when I was on my own, and showed me or taught me many skills that have helped me. Some of these things included: independent living skills, banking skills, paying bills, meal planning, budgeting, how to get around in the community, how to get an apartment.

b. I learned some things at home that have helped me live on my own. My parents mainly just talked about things I needed to know but we never actually did them.

c. I did not learn anything at home that has helped me live on my own. My family was not really too involved in teaching me to be successful. Sometimes my family was a barrier to my success.

\section{How would you rate your school preparation for} transition to college?

a. Lots of helpful preparation for college

b. Average preparation for college

c. Very little preparation for college

\section{Author's Note}

This work was supported by U.S. Department of Education Grant, University of Kansas Secondary Special Education and Transition Leadership Personnel Preparation Project (KU-SET; 2005-2010), U.S. Department of Education, Office of Special Education Programs.

\section{References}

Alwell, M., \& Cobb, B. (2006). A systematic review of the effects of curricular interventions on the acquisition of functional life skills by youth with disabilities. What Works Transition Research Synthesis. Retrieved February 13, 2009, from http://www.nsttac.org/pdf/life_skills.pdf

Babyak, M. A., Snyder, C. R., \& Yoshinobu, L. (1993). Psychometric properties of the Hope Scale: A confirmatory factor analysis. Journal of Research in Personality, 27, 154-169.

Blackorby, J., \& Wagner, M. (1996). Longitudinal postschool outcomes of youth with disabilities: Findings from the National Longitudinal Transition Study. Exceptional Children, 63, $151-165$.

Brewer, D. (2006). Transition quality indicators. Ithaca, NY: Cornell University. Retrieved October 1, 2008, from http://www .ilr.cornell.edu/edi/transqual

Carter, E. W., Lane, K. L., Pierson, M. R., \& Glaeser, B. (2006). Self-determination skills and opportunities of transition-age youth with emotional disturbance and learning disabilities. Exceptional Children, 72, 333-346.

Cobb, B., \& Alwell, M. (2008). Transition planning/coordinating interventions for youth with disabilities: A systematic review. What Works Transition Research Synthesis. Retrieved February 13, 2009, from http://www.nsttac.org/pdf/what_works/2d_ full_text.pdf

Cobb, B., Lehmann, J., Newman-Gonchar, R., \& Alwell, M. (2008). Self-determination for students with disabilities: A narrative meta-synthesis. What Works Transition Research Synthesis. Retrieved February 7, 2009, from http:/www.nsttac.org/pdf/what_works/2d_full_text.pdf

deFur, S. H., Todd-Allen, M., \& Getzel, E. E. (2001). Parent participation in the transition planning process. Career Development for Exceptional Individuals, 24, 19-36.

Devlieger, P. J., \& Trach, J. S. (1999). Mediation as a transition process: The impact on postschool employment outcomes. Exceptional Children, 65, 507-523.

Durlak, C. M., Rose, E., \& Bursuck, W. D. (1994). Preparing high school students with learning disabilities for the transition to postsecondary education: Teaching the skills of self-determination. Journal of Learning Disabilities, 27, 51-59.

Eckes, S. E., \& Ochoa, T. A. (2005). Students with disabilities: Transitioning from high school to higher education. American Secondary Education, 33(3), 6-20. 
Field, S., Sarver, M. D., \& Shaw, S. F. (2003). Self-determination: A key to success in postsecondary education for students with learning disabilities. Remedial and Special Education, 24, 339-349.

Finn, D., Getzel, E. E., \& McManus, S. (2008). Adapting the selfdetermined learning model for instruction of college students with disabilities. Career Development for Exceptional Individuals, 31(2), 85-93.

Getzel, E. E., \& Thoma, C. A. (2008). Experiences of college students with disabilities and the importance of self-determination in higher education settings. Career Development for Exceptional Individuals, 31, 77-84.

Greene, G., \& Albright, L. (1995). "Best practices" in transition services: Do they exist? Career Development for Exceptional Individuals, 18(1), 1-2.

Green, S. B., \& Salkind, N.J. (2008). Using SPSS for Windows and Macintosh: Analyzing and understanding data (5th ed.). Upper Saddle River, NJ: Prentice Hall.

Harris, R., \& Robertson, J. (2001). Successful strategies for college bound students with learning disabilities. Preventing School Failure, 45, 125-131.

Hong, B. S. S., Ivy, F. W., Gonzalez, H. R., \& Ehrensberger, W. (2007). Preparing students for postsecondary education. Teaching Exceptional Children, 40, 32-38.

Individuals With Disabilities Education Improvement Act of 2004. Pub. L. No. 108-446.

Jameson, D. R. (2007). Self-determination and success outcomes of two year college students with disabilities. Journal of College Reading and Learning, 37, 26-46.

Karvonen, M., Test, D., Wood, W. M., Browder, D., \& Algozzine, B. (2004). Putting self-determination in practice. Exceptional Children, 71, 23-41.

Kohler, P. D. (1996). Taxonomy for transition programming: Reflecting on transition-focused education. Kalamazoo: Western Michigan University.

Kohler, P. D. (2007). Team planning tool for state capacity building: Secondary education and transition services. Charlotte, NC: National Secondary Transition Technical Assistance Center. Retrieved February 3, 2009, from http://www.nsttac.org/ pdf/state_cap_building_tool.pdf

Konrad, M., Walker, A. R., Fowler, C. H., Test, D. W., \& Wood, W. M. (2008). A model for aligning self-determination and general curriculum standards. Teaching Exceptional Children, 40, 53-64.

Lackaye, T., \& Margalit, M. (2008). Self-efficacy, loneliness, effort and hope: Developmental differences in the experiences of students with learning disabilities and their non-learning disabled peers in the two age groups. Learning Disabilities: A Contemporary Journal, 6, 1-20.

Leeson, P., Ciarrochi, J., \& Heaven, P. (2008). Cognitive ability, personality and academic performance in adolescence. Personality and Individual Differences, 45, 630-635.
Lehmann, J. P., Bassett, D. S., \& Sands, D. J. (1999). Students' participation in transition-related actions: A qualitative study. Remedial and Special Education, 20, 160-169.

Lindstrom, L., Doren, B., Metheny, J., Johnson, P., \& Zane, C. (2007). Transition to employment: Role of the family in career development. Exceptional Children, 73, 348-366.

Lopez, S. J., Snyder, C. R., \& Pedrotti, J. T. (2003). Hope: Many definitions, many measures. In S. J. Lopez \& C. R. Snyder (Eds.), Positive psychological assessment (pp. 91-107). Washington, DC: American Psychological Association.

Martin, J. E., Marshall, L. H., \& Sale, P. (2004). A 3-year study of middle, junior high, and high school IEP meetings. Exceptional Children, 70, 285-297.

Martin, J. E., Van Dycke, J. L., Greene, B. A., Gardner, J. E., Christensen, W. R., Woods, L. L., et al. (2006). Direct observation of teacher-directed IEP meetings: Establishing the need for student IEP meeting instruction. Exceptional Children, 72, 187-200.

Mason, C., Field, S., \& Sawilowsky, S. (2004). Implementation of self-determination activities and student participation in IEPs. Exceptional Children, 70, 441-451.

Morningstar, M. E. (1997). Critical issues in career development and employment preparation for adolescents with disabilities. Remedial and Special Education, 18, 307-320.

Morningstar, M. E. (2006). Quality Indicators of Exemplary Transition Programs Needs Assessment Instrument. Lawrence: University of Kansas.

Morningstar, M., Kleinhammer-Tramill, J., \& Lattin, D. (1999). Using successful models of student-centered transition planning and services for adolescents with disabilities. Focus on Exceptional Children, 31, 1-19.

Morningstar, M. E., Turnbull, A. P., \& Turnbull, H. R., III (1995). What do students with disabilities tell us about the importance of family participation in transition from school to adult life? Exceptional Children, 62, 249-260.

National Council on Disability. (2004a). Improving educational outcomes for students with disabilities. Retrieved September 25, 2008, from http://www.ncd.gov/newsroom/publications/2004/pdf/educationoutcomes.pdf

National Council on Disability. (2004b). Transition and postschool outcomes for youth with disabilities: Closing the gaps to postsecondary education and employment. Retrieved September 25, 2008, from http:/www.ncd.gov/newsroom/publications/2000/ transition_11-01-00.htm

Newman, L. (2005) Postsecondary education participation of youth with disabilities. In M. Wagner, L. Newman, R. Cameto, N. Garza, \& P. Levine, After high school: A first look at postschool experiences of youth with disabilities. Retrieved November 11, 2008, from http://www.nlts2.org/reports/2005_04/nlts2 report_2005_04_ch4.pdf

Noonan, P. N., Morningstar, M. E., \& Gaumer Erickson, A. (2008) Improving interagency collaboration: Effective strategies used 
by high performing local districts and communities. Career Development for Exceptional Individuals, 31, 132-143.

Powers, L. E., Turner, A., Ellison, R., Matuszewski, J., Wilson, R., Phillips, A., et al.. (2001). TAKE CHARGE for the Future: A Controlled Field-Test of a Model to Promote Student Involvement in Transition Planning. Career Development for Exceptional Individuals. 24(1) 89-104

Raosoft. (2007). EZSurvey (Version 2007b) [Computer software]. Seattle, WA: Author.

Rehfeldt, J. D. (2006). An investigation into the effects of using the Transition Planning Inventory on IEP goal development and locus of control. Dissertation Abstracts International, 68 (01). (AAT No. 3251347)

Shogren, K. A., Lopez, S. J., Wehmeyer, M. L., Little, T. D., \& Pressgrove, C. L. (2006). The role of positive psychology constructs in predicting life satisfaction in adolescents with and without cognitive disabilities: An exploratory study. Journal of Positive Psychology, 1, 37-52.

Snyder, C. R., Harris, C., Anderson, J. R., Holleran, S. A., Irving, L. M., Sigmon, S. T., et al. (1991). The will and the ways: Development and validation of an individual-differences measure of hope. Journal of Personality and Social Psychology, 60, 570-585.

Snyder, C. R., Hoza, B., Pelham, W. E., Rapoff, M., Ware, L., Danovsky, M., et al. (1997). The development and validation of the Children's Hope scale. Journal of Pediatric Psychology, 22, 399-421.

Snyder, C. R., Shorey, H. S., Cheavens, J., Pulvers, K. M., Adams, V. S., \& Wiklund, C. (2002). Hope and academic success in college. Journal of Educational Psychology 94, 820-826.

Test, D. W., Mason, C., Hughes, C., Konrad, M., Neale, M., \& Wood, W. (2004). Student involvement in individualized education program meetings. Exceptional Children, 70, 391-412.

Thoma, C. A., \& Getzel, E. E. (2005). "Self-determination is what it's all about": What postsecondary students with disabilities tell us are important considerations for success. Education and Training in Developmental Disabilities, 40, 234-242.

Thoma, C. A., Nathanson, R., Baker, S. R., \& Tamura, R. (2002). Self-determination: What do special educators know and where do they learn it? Remedial and Special Education, 23, 242-247.

Thompson, J. R., Fulk, B. M., \& Piercy, S. W. (2001). Do individualized transition plans match the postschool projections of students with learning disabilities and their parents? Career Development for Exceptional Individuals, 23, 3-25.

Wagner, M., Newman, L., Cameto, R., Garza, N., \& Levine, P. (2005). After high school: A first look at the post school experiences of youth with disabilities: A report from the National Longitudinal Transition Study-2 (NLTS2). Menlo Park, CA: SRI International.

Wehmeyer, M. L. (1995). The Arc's Self-Determination Scale: Procedural guidelines. Arlington, TX: The Arc of the
United States. Retrieved June 24, 2009, from http:/www .eric.ed.gov/ERICDocs/data/ericdocs2sq1/content_storage _01/0000019b/80/16/38/0f.pdf

Wehmeyer, M. L. (2004). Beyond self-determination: Causal agency theory. Journal of Developmental and Physical Disabilities, 16, 337-359.

Wehmeyer, M. L., \& Field, S. (2007). Self-determination: Instructional and assessment strategies. Thousand Oaks, CA: Corwin Press.

Wehmeyer, M. L., \& Kelchner, K. (1995). The Arc's SelfDetermination Scale. Arlington, TX: Arc National Headquarters.

Wehmeyer, M. L., Morningstar, M. E., \& Husted, D. (1999). Family involvement in transition planning and program implementation. Austin, TX: ProEd.

Wehmeyer, M. L., \& Palmer, S. B. (2003). Adult outcomes for students with cognitive disabilities three-years after high school: The impact of self-determination. Education and Training in Developmental Disabilities, 38, 131-144.

\section{About the Authors}

Mary E. Morningstar is an associate professor of special education at the University of Kansas. Her research interests include supporting families and youth with disabilities during transition planning, teacher preparation and professional development for transition, and youth with significant disabilities.

Bruce B. Frey is an associate professor of educational psychology and research at the University of Kansas. His research interests include classroom assessment, program evaluation, and the Levels of Collaboration Scale.

Patricia M. Noonan is an assistant research professor at the University of Kansas. Her research interests include interagency collaboration for transition and systems change within secondary schools.

Jennifer $\mathbf{N g}, \mathrm{PhD}$, is a faculty member in the department of educational leadership and policy studies at the University of Kansas. Her research interests include multicultural issues related to race, class, and other equity concerns in education.

Beth Clavenna-Deane is a doctoral candidate in special education at the University of Kansas.

Perry Graves is a doctoral student in special education at the University of Kansas.

Ryan Kellems is a doctoral candidate in special education at the University of Kansas.

Zach McCall is a doctoral student in special education at the University of Kansas. 
Mary Pearson is a doctoral student in special education at the University of Kansas.

Diana Bjorkman Wade is a doctoral student in special education at the University of Kansas.
Kendra Williams-Diehm is an assistant professor of special education at the University of Oklahoma. She currently conducts research on self-determination and transition/postsecondary outcomes for students with disabilities. 